\title{
Study of lithium glassy solid electrolyte/electrode interface by impedance analysis
}

\author{
A KARTHIKEYAN ${ }^{\dagger}$, P VINATIER and A LEVASSEUR* \\ Institut de Chimie de la Matière Condensée de Bordeaux - C.N.R.S. et Ecole Nationale Supérieure de Chimie et de \\ Physique de Bordeaux, BP 108, F-33402 Talence Cedex, France \\ ${ }^{\dagger}$ Present address: Departamento de Engenharia de Materiais, Instituto Superior Technico, Av. Rovisco Pais \\ 1049-001, LISBOA Codex
}

MS received 7 April 2000

\begin{abstract}
Cells of lithium ion conducting glassy electrolyte $\mathrm{Li}_{2} \mathrm{SO}_{4}-\mathrm{Li}_{2} \mathrm{O}-\mathrm{B}_{2} \mathrm{O}_{3}$ with different combinations of electrodes (stainless steel blocking electrode, lithium non-blocking electrode and $\mathrm{TiS}_{2}$ electrode) have been prepared. The a.c. impedance measurements of the cells have been studied at elevated temperature as a function of time. The circuit elements such as bulk resistance, double layer capacitance and charge transfer resistance have been inferred and their time dependence studied. The results show that the electrolyte and the interface are chemically very stable with the different types of electrodes studied here.
\end{abstract}

Keywords. Solid electrolyte; lithium ion conducting glass; microbattery; electrode-electrolyte compatibility; impedance spectroscopy.

\section{Introduction}

Lithium secondary batteries have been paid more attention for several years owing to their promising applications ranging from portable devices to vehicle traction. Many new positive electrode materials $\left(\mathrm{LiCoO}_{2}, \mathrm{LiMn}_{2} \mathrm{O}_{4}\right.$, etc) and anode materials ( $\mathrm{Li}$, carbon, etc) are being investigated to improve the battery performance. A very large amount of publications report on these matters. A good overview of recent progress done in the field of lithium batteries is given for example in the special issue of Journal of Power Sources related to the 8th and 9th international meeting on lithium batteries (Proceedings of the eighth international meeting on lithium batteries, 1997; Proceedings of the ninth international meeting on lithium batteries, 1999). The performance of a battery depends on many parameters such as (i) chemical potential of the anodic and cathodic reactions, (ii) intercalation and deintercalation properties of the electrodes, (iii) ionic conductivity of the electrolyte, (iv) electrode-electrolyte interfacial compatibility and chemical durability. Widespread investigations are being carried out on all these matters. In the more specific case of microbatteries using an inorganic solid electrolyte in contact with lithium, the fourth point mentioned above is very important. (A microbattery is a solid state battery designed and built with thin film technology and in which the thickness of each part is in $\mu \mathrm{m}$ range (Levasseur et al 1989; Jones and Ackridge 1996; Neudecker et al 1999)). The integrity between the solid electrolyte and electrode is one of the vitally impor-

\footnotetext{
*Author for correspondence
}

tant requirements for the solid state battery to achieve high current density, more cyclability and longer shelf life.

A reliable solid state battery electrode and electrolyte interface should not have any spurious geometrical, physical and chemical effects. However, there are very few studies concerning electrode-solid electrolyte interface (Armstrong and Mason 1973; Kimura et al 1975; Bagotzky 1993; Moon et al 1997). Most of the works focus on the study of interface capacitance and its dependence on concentration of a liquid electrolyte and applied potential. However it is very important to investigate the interface of the solid electrolyte with different types of electrodes and to study their time dependence. We have carried out the impedance measurements of the glassy solid electrolyte $\mathrm{Li}_{2} \mathrm{SO}_{4}-\mathrm{Li}_{2} \mathrm{O}-\mathrm{B}_{2} \mathrm{O}_{3}$ sandwiched between different combinations of electrodes. This glassy solid electrolyte was developed earlier in this laboratory and used for solid state microbattery applications (Levasseur et al 1983). Stainless steel blocking electrodes, lithium non-blocking electrodes and $\mathrm{TiS}_{2}$ real electrodes were used in the present study in five different cell configurations. Measurements were carried out at room temperature and at high temperature $\left(100^{\circ} \mathrm{C}\right)$. Studies carried out at high temperature for a short time (few days), where the chemical activity is very high, are in essence long time studies at ambient conditions for experiments of the present type.

\section{Experimental}

Ion conducting glass, $31 \% \mathrm{Li}_{2} \mathrm{SO}_{4}-31 \% \mathrm{Li}_{2} \mathrm{O}-38 \% \mathrm{~B}_{2} \mathrm{O}_{3}$, was prepared by conventional melt quenching method. 
This composition was found earlier to give the highest ionic conductivity (Levasseur et al 1983). Mixer of analar grade $\mathrm{Li}_{2} \mathrm{SO}_{4}, \mathrm{LiOH}$ and $\mathrm{B}_{2} \mathrm{O}_{3}$ chemicals, weighed in a dry box to prevent hydration, was heated in a platinum crucible at $300^{\circ} \mathrm{C}$ (for $1 \mathrm{~h}$ for water to evaporate) and at $900^{\circ} \mathrm{C}$ (for $1 \mathrm{~h}$ to get homogenous melt formation with frequent stirring). Glass pieces were obtained by quenching the melt between pre-heated $\left(150^{\circ} \mathrm{C}\right)$ stainless steel plates. The glasses thus obtained were stored in an argonfilled dry box and consequent operations were carried out in the dry box to avoid effects of moisture. Pellets of finely ground glass (thickness about 1-2 mm) were prepared and sandwiched between different electrodes in the following configurations.

Cell A: Stainless steel // glassy electrolyte // stainless steel; Cell B: Stainless steel // glassy electrolyte // lithium metal; Cell C: Lithium metal // glassy electrolyte // lithium metal; Cell D : Stainless steel // glassy electrolyte // $\mathrm{TiS}_{2}$;

Cell E : $\mathrm{TiS}_{2} / /$ glassy electrolyte // $\mathrm{TiS}_{2}$.

Flat and highly polished electrodes were used and the cell assembly was mounted between stainless steel supports in an argon-filled conductivity set up for impedance measurements. All the lead and other external effects were carefully minimized. The impedance of the cell was measured using a Solartron frequency response analyser (model 1170) coupled with an electrochemical interface (model $1186)$ in the frequency range of $1 \mathrm{MHz}$ to $1 \mathrm{mHz}$. The impedance measurements were carried out at $100^{\circ} \mathrm{C}$ during a two-week time in regular intervals.

\section{Results and discussion}

\subsection{Impedance plots for various combinations of electrodes}

All the cells exhibit a high frequency semicircular arc which is typical of parallel combination of bulk resistance and bulk capacitance. A low frequency $\sim 90^{\circ}$ straight line has been observed for the cell with stainless steel blocking electrode on either side (cell A). This is typical of the formation of double layer capacitance at the blocking electrode/electrolyte interface. The imaginary part $\left(Z^{\prime \prime}\right)$ of cell A has reached values as high as $30 \mathrm{M} \Omega$ at low frequency. There is no low frequency straight line for cell C (with two non-blocking lithium electrodes) as expected, where the thermodynamic parameters do not change at the interface. This assures the free motion of lithium ions across the interface (into and from electrode). It is interesting to see that in an asymmetric combination lithium/glass/stainless steel (cell B), the formation of a low frequency straight line is not clear even up to a frequency of $1 \mathrm{mHz}$, as shown in figure 1a. Only a very small arc, distorted in shape, is seen (this also diminishes after some time, see figure 1a). There have been even earlier only few instances of the observation of a welldefined double layer capacitance when asymmetric cell was used. However the reasons for non-detectability are still not clearly known. As far as cell D is concerned, two semicircular arcs and a low frequency $45^{\circ}$ straight line (typical of diffusion in a real electrode, $\mathrm{TiS}_{2}$ ) is observed, as shown in figure $1 \mathrm{~b}$. One high frequency semicircular arc and a $45^{\circ}$ low frequency straight line has been observed for cell $\mathrm{E}$ and the conductivity of the glassy electrolyte has been obtained from this cell.

The idealized equivalent circuit for the glassy solid electrolyte sandwiched between two electrodes (of any
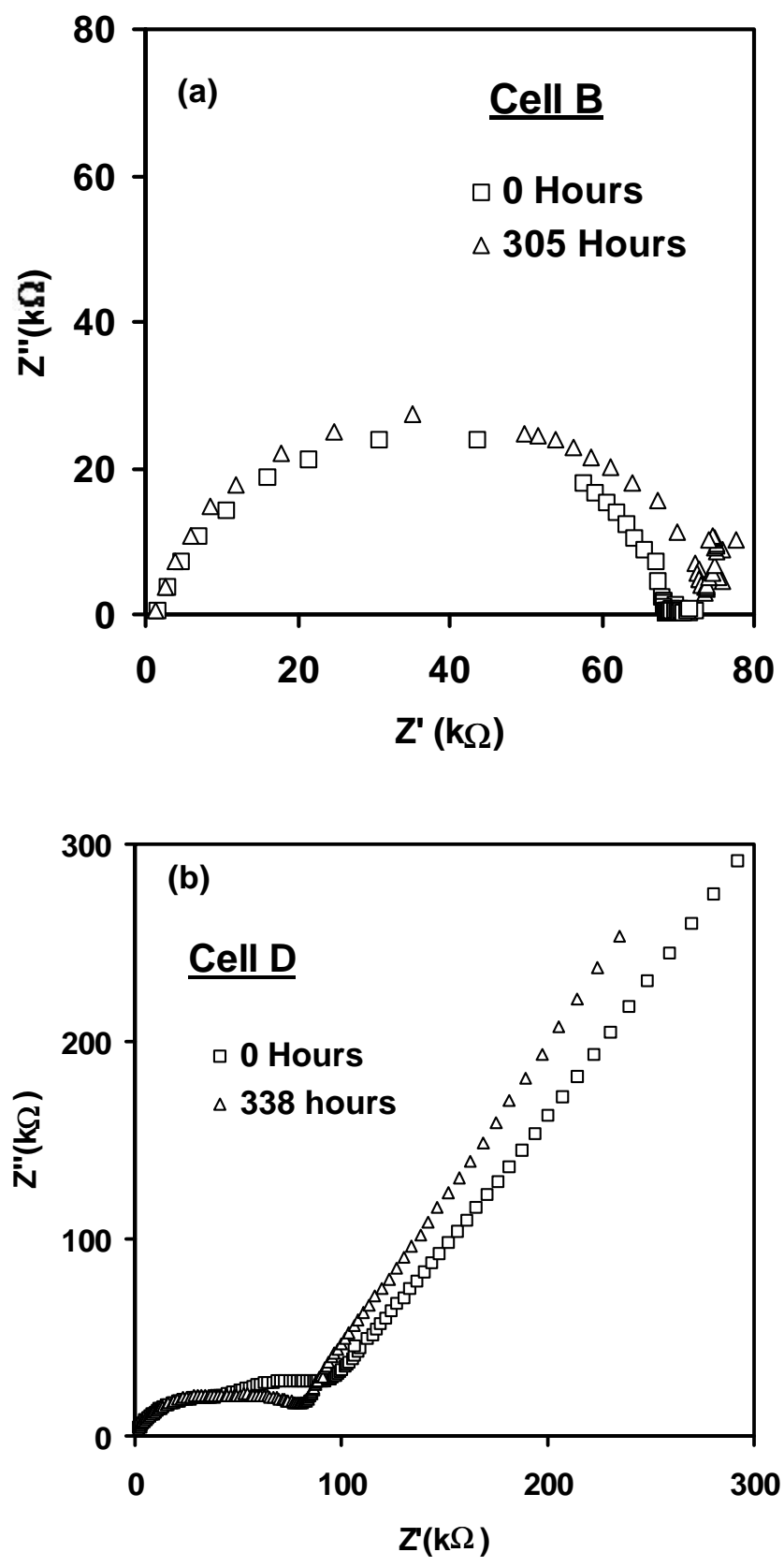

Figure 1. Impedance plots of (a) cell B and (b) cell D, at $100^{\circ} \mathrm{C}$ at the beginning and after a long time. 
type), taking into account the various elements, is given in figure 2a (Macdonald 1987). Glasses are isotropic and free from grain boundary effects (grain boundary resistance and capacitance). Thus the glassy electrolytes have only two elements, bulk resistance $\left(R_{\mathrm{b}}\right)$ and bulk capacitance $\left(C_{\mathrm{b}}\right)$, in parallel and are responsible for the high frequency semicircular arc seen in the impedance plots of the cells studied here. The lithium ion conductivity was found to be more or less similar in different cells, and it was $1.05 \times 10^{-7} \mathrm{~S} / \mathrm{cm}\left(\right.$ at $25^{\circ} \mathrm{C}$ ) with activation energy of $0.56 \mathrm{eV}$ in cell $\mathrm{E}$. The percentage of error in the calculated bulk resistance values in cells A and D was slightly more compared to other cells because the formation of high frequency semicircular arc was not complete for these cells. The bulk capacitance $C_{\mathrm{b}}$ was found to be around $0.85 \times 10^{-10} \mathrm{~F} / \mathrm{cm}^{2}$. The elemental circuits for the different symmetrical electrodes are given in figures $2 \mathrm{~b}-\mathrm{d}$ and are discussed as follows.

The non-blocking electrode (lithium) has a negligible resistance for charge transfer $\left(R_{\mathrm{ct}}\right)$ and the effective equivalent circuit of cell $\mathrm{C}$ reduces to a RC parallel circuit. The effect of the blocking electrodes is ideally merely capacitive due to the formation of a double layer. The double layer capacitance has two parts in series (i) the Helmholtz compact double layer capacitance and (ii) diffuse Gouy-Chapman double layer capacitance for a symmetrical electrolyte (Macdonald 1987). The compact (or inner) layer capacitance is a slowly varying function of the applied potential and is around a few $\mathrm{mF}$. The diffuse layer capacitance varies exponentially with voltage. For the current measurements a small voltage of $5 \mathrm{mV}$ was used and at this potential the diffuse double layer capacitance was expected to be very low. The double layer capacitance of the cell A, calculated by fitting the impedance plot and by admittance plot, lie between 0.5 to $1.0 \mathrm{nF} / \mathrm{cm}^{2}$. This capacitance is attributed to the diffuse layer capacitance. When connected in series with the inner layer capacitance, the former is predominant.

The intersection of the low frequency straight line with real axis for cell $\mathrm{A}$ is not exactly $90^{\circ}$ but less than that.

(a)

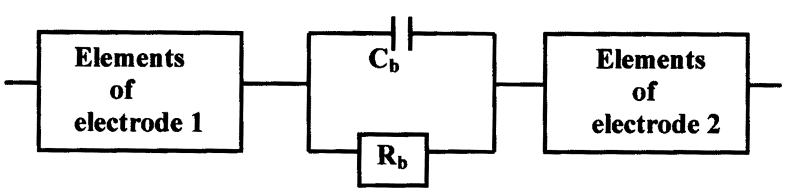

(b)

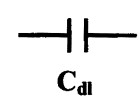

(c)

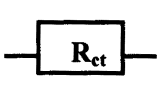

(d)

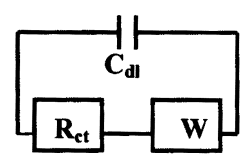

Figure 2. (a) General equivalent circuit for the glassy electrolyte sandwiched between two electrodes. The circuit elements of (b) blocking electrode - stainless steel, (c) non-blocking electrode - lithium and $(\mathbf{d})$ real electrode $-\mathrm{TiS}_{2}$.
This could be due to the irregularities in the electrode/ electrolyte interface geometry. Hence a capacitance plus other constant phase elements could represent the elemental effect of stainless steel electrode. In addition to the double layer capacitance, the $\mathrm{TiS}_{2}$ electrode has a Warburg resistance $(W)$, in series with $R_{\mathrm{ct}}$, typical of lithium ion diffusion in the electrode (Macdonald 1987). The diffusion in electrode is observed as a low frequency $45^{\circ}$ straight line in the impedance plots (figure $1 \mathrm{~b}$ ). The additional semicircular arc in the mid-frequency range is due to the parallel combination of double layer capacitance $C_{\mathrm{dl}}$ and charge transfer resistance $R_{\mathrm{ct}}$. The charge transfer resistance of the cell is $58 \mathrm{k} \Omega$.

\subsection{Time dependence at $100^{\circ} \mathrm{C}$}

The bulk resistance $\left(R_{\mathrm{b}}\right)$ of cells $\mathrm{A}-\mathrm{D}$ at $100^{\circ} \mathrm{C}$ as a function of time is given in figure 3. The electrolyte resistance remained almost constant even up to $500 \mathrm{~h}$. No change in resistivity of the electrolyte due to crystallization or any other effects has been observed as shown in figure 3. This shows that the glassy solid electrolyte, $\mathrm{Li}_{2} \mathrm{SO}_{4}-\mathrm{Li}_{2} \mathrm{O}-$ $\mathrm{B}_{2} \mathrm{O}_{3}$, is thermally very stable as required for solid state battery applications. Moreover, the electrolyte surface is also chemically very stable with the different types of electrodes studied here. At ambient temperatures, where the chemical activity is far less, the stability is expected to be even higher. However at room temperature the effect of moisture will be stressed which can be minimized by providing the battery with a tight sealing.

The admittance plot scaled by the frequency is a measure of the capacitance and their intercepts with $y$ axis giving associated capacitance values. The time dependence of bulk $\left(C_{\mathrm{b}}\right)$ and double layer capacitance $\left(C_{\mathrm{dl}}\right)$ obtained in this way for cell $A$ is plotted in figure 4. This figure shows that bulk capacitance is almost constant with time

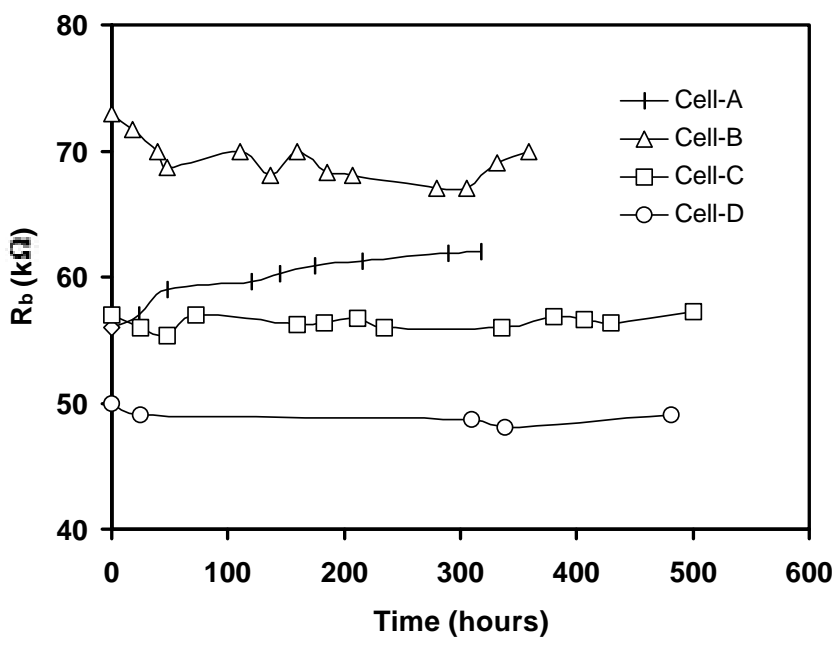

Figure 3. Time dependence of the bulk resistance in different cells at $100^{\circ} \mathrm{C}$. 


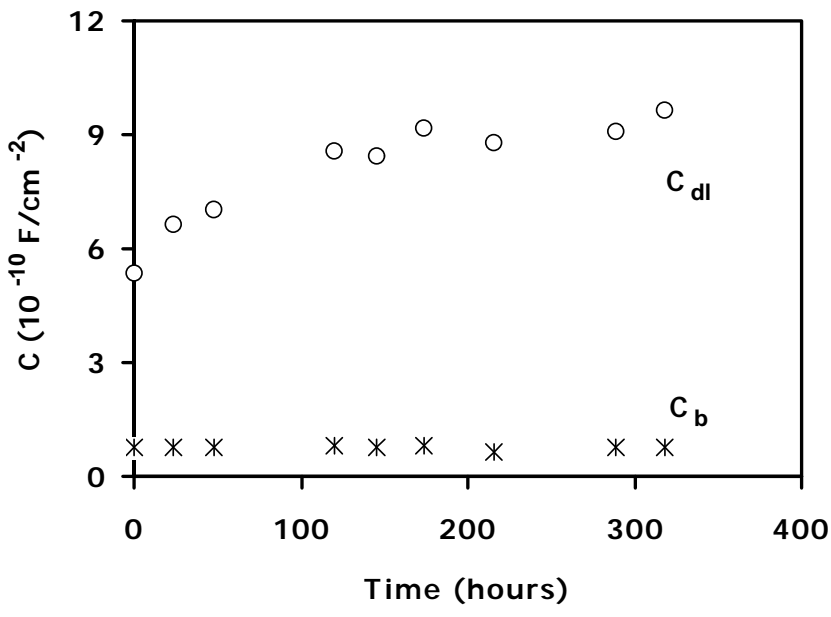

Figure 4. Bulk capacitance $\left(C_{\mathrm{b}}\right)$ and double layer capacitance $\left(C_{\mathrm{dl}}\right)$ as a function of time in cell $\mathrm{A}$.

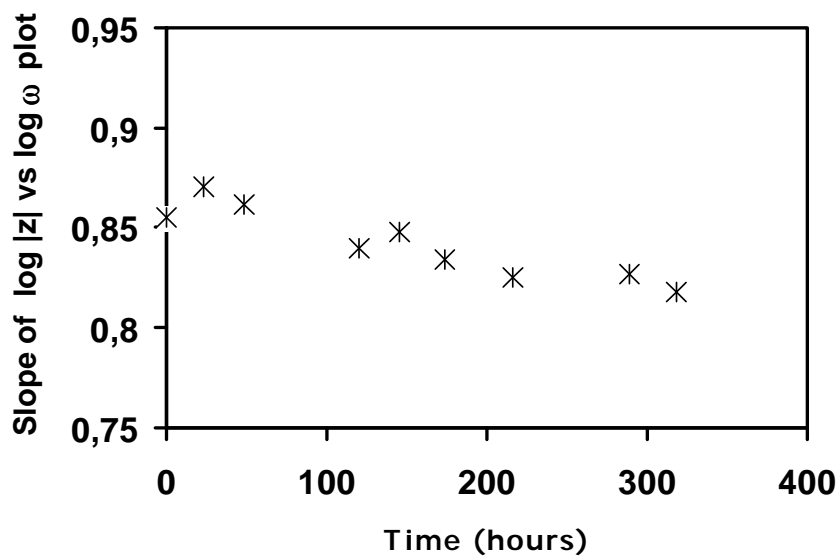

Figure 5. Time dependence of the slope of the $\log |Z|$ vs $\log \omega$ plots for cell A.

and double layer capacity initially slightly increases and thereafter stabilizes. This indicates that the interface is very stable and void of any unwarranted effects.

The slope of the $\log |Z|$ vs $\log \omega$ gives an idea of phase elements in the circuit (Macdonald 1987). For example for a merely capacitive element (phase change $90^{\circ}$ ), the slope is -1.0 and the slope is zero for a merely resistive element (no phase change). In figure 5 the slope of the $\log |Z|$ vs $\log \omega$ plot of cell $\mathrm{A}$ at low frequency is plotted as a function of time. The slope is $\sim 0.85$ which is close to but less than one. This may be due to the roughness in the interface and is responsible for the inclination of the low frequency straight line in the impedance plots as seen earlier. The slope decreases slightly with time indicating a small resistive increase in the roughness of electrode/ electrolyte interface. This is responsible for the small increase in electrolyte resistance observed earlier for cell A (figure 3). For cell B the slope of the $\log |Z|$ vs $\log \omega$ plots at low frequency is zero (not shown). It also clearly

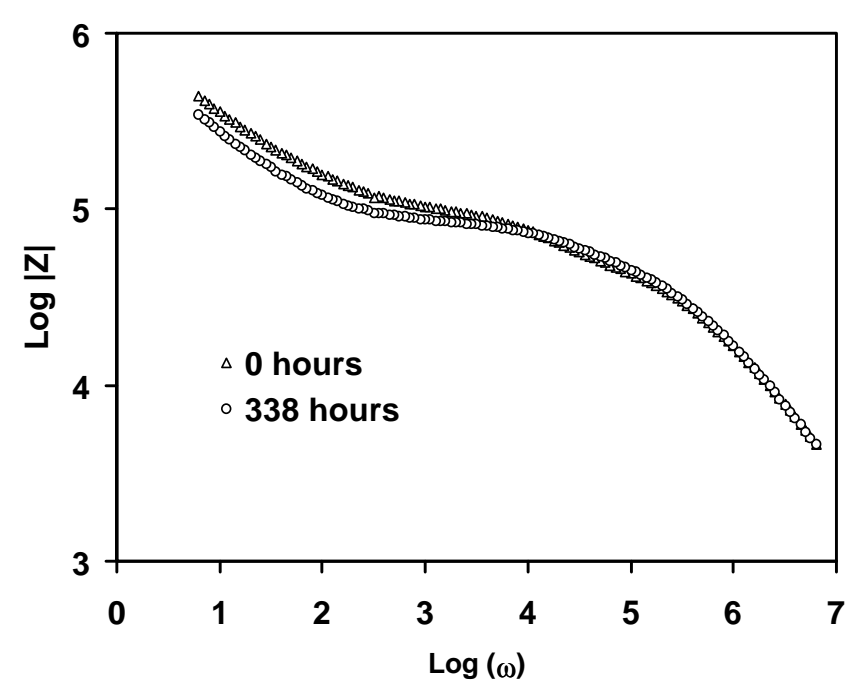

Figure 6. $\log |Z|$ vs $\log \omega$ plots for cell $D$ at the beginning and at $338 \mathrm{~h}$.

indicates that the double layer capacitance of the stainless steel interface with electrolyte is not observed in the asymmetrical cell configuration. The $\log |Z|$ vs $\log \omega$ plot for cell $\mathrm{D}$ at two different times is shown in figure 6 . There is no change in the high frequency region of these plots with time. At intermediate frequencies the slope decreases with time where the double layer capacitance and charge transfer resistance is observed. This is due to the decrease in charge transfer resistance and does not indicate increase in roughness of the electrode/electrolyte interface, because no noticeable increase in double layer capacitance (or slope) is observed with time.

\section{Conclusions}

The following conclusions have been drawn from the present studies. (I) The glassy electrolyte $\left(\mathrm{Li}_{2} \mathrm{SO}_{4}-\mathrm{Li}_{2} \mathrm{O}-\right.$ $\mathrm{B}_{2} \mathrm{O}_{3}$ ) is thermally very stable and no unwanted effects on electrochemical parameters are seen, even for a very long time. So this glassy electrolyte is suitable for battery applications. (II) No noticeable spurious electrode/electrolyte interfacial chemical or physical effects are seen with the different types of electrodes studied here. The interfacial integrity and compatibility is expected to be even better in thin film batteries, where the contacts are made by physical vapour deposition methods. The results obtained in the present study are important for the development of solid state batteries. It is generally believed that solid-solid interface contacts are poor and that the contact roughness increases quickly with time and may be detrimental to the battery cycle and shelf life. However, the present results do not show any significant unwanted effects with time and interfaces are also found to be chemically stable. This is more encouraging for the fabrication of solid state thin film lithium batteries for low power requirements. 


\section{References}

Armstrong D and Mason R 1973 J. Electroanal. Chem. 41231 Bagotzky V S 1993 J. Electroanal. Chem. 357251

Jones S D and Akridge J R 1996 Solid State Ionics 86-88 1291 Kimura N, Osaki T and Toshima S 1975 Bull. Chem. Soc. Jap. 48830 Levasseur A, Kbala M, Hagenmuller P, Couturier G and Danto Y 1983 Solid State Ionics 9/10 1439

Levasseur A, Menetrier M, Dormoy R and Meunier G 1989 Mater. Sci. Eng. B3 5
Macdonald J R (ed.) 1987 Impedance spectroscopy (Wiley Interscience)

Moon S I, Kim J U, Jin B S, Hyung Y E, Yun M S, Gu H B and Ko Y 1997 J. Power Sources 68660

Neudecker B J, Zuhr R A and Bates J B 1999 J. Power Sources 81-82 27

Proceedings of the eighth international meeting on lithium batteries 1997 J. Power Sources 68 p. 1-739

Proceedings of the ninth international meeting on lithium batteries 1999 J. Power Sources 81-82 p. 1-925 